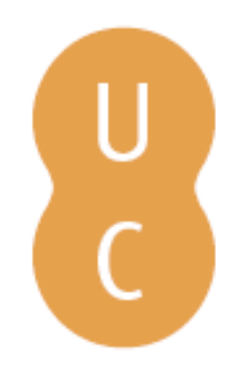

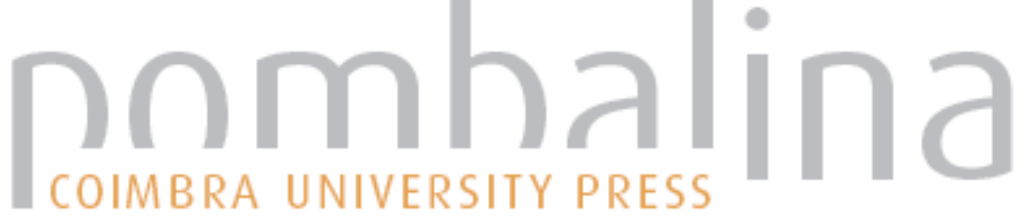

\section{A Lusitânia no tempo de Ovídio: metamorfoses de uma província}

\author{
Autor(es): $\quad$ Guerra, Amílcar
}

Publicado por: Centro de Estudos Clássicos e Humanísticos; Imprensa da Universidade

URL

persistente: URI:http://hdl.handle.net/10316.2/31689

DOI: $\quad$ DOI:http://dx.doi.org/10.14195/978-989-8281-47-0_14

Accessed : $\quad$ 26-Apr-2023 01:13:00

A navegação consulta e descarregamento dos títulos inseridos nas Bibliotecas Digitais UC Digitalis, UC Pombalina e UC Impactum, pressupõem a aceitação plena e sem reservas dos Termos e Condições de Uso destas Bibliotecas Digitais, disponíveis em https://digitalis.uc.pt/pt-pt/termos.

Conforme exposto nos referidos Termos e Condições de Uso, o descarregamento de títulos de acesso restrito requer uma licença válida de autorização devendo o utilizador aceder ao(s) documento(s) a partir de um endereço de IP da instituição detentora da supramencionada licença.

Ao utilizador é apenas permitido o descarregamento para uso pessoal, pelo que o emprego do(s) título(s) descarregado(s) para outro fim, designadamente comercial, carece de autorização do respetivo autor ou editor da obra.

Na medida em que todas as obras da UC Digitalis se encontram protegidas pelo Código do Direito de Autor e Direitos Conexos e demais legislação aplicável, toda a cópia, parcial ou total, deste documento, nos casos em que é legalmente admitida, deverá conter ou fazer-se acompanhar por este aviso.

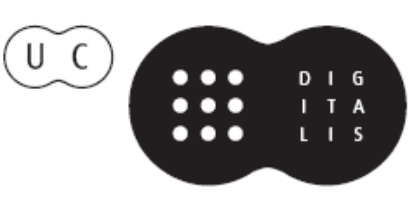




\section{Sociedade, Poder e Cultura no Tempo de Ovídio}

Maria Cristina de Sousa Pimentel e Nuno Simões Rodrigues (Coords.) 


\section{A Lusitânia no Tempo de Ovídio: MeTAMORFoses de UMA PROVÍNCIA}

Amílcar Guerra

Universidade de Lisboa

1. A vida de Ovídio (43 a. C. - 17/18 d. C.) decorre ao longo de um período decisivo na história da Hispânia, correspondente à mais profunda transformação que ocorreu neste território durante o domínio romano. $\mathrm{O}$ principal responsável pelas substanciais alterações que aqui se registam é precisamente o mesmo que o conduz a um penoso desterro, no lado oposto do império: Augusto, o "pai da pátria». Um pai rigoroso com o poeta como o era com a reorganização das terras que lhe foram confiadas e cuja gestão assumiu com vaidade e empenho, acreditando ser essa a solução única para a salvação da res publica.

Ovídio, como a maioria dos itálicos, tinha da Lusitânia uma ideia bastante vaga. Essa província romana, criada poucos anos depois de ter chegado a Roma, situada no finis terrarum, não deveria representar muito mais do que um mundo distante e ignoto, do qual se conheciam apenas algumas particularidades exóticas, muitas vezes de contornos míticos. Todavia, a um homem culto e empenhado na vida pública, não deveriam ser estranhas as narrativas dos aguerridos companheiros de Viriato e as construções idealizadas da personalidade do caudilho lusitano, que Posidónio erguera à condição de rei, herói e modelo de sabedoria ${ }^{1}$.

Conhecedor da literatura do seu tempo e de muitas auctoritates, não deveriam ter passado despercebidos ao Sulmonense alguns dos abundantes reflexos que os episódios passados há cerca de um século no Ocidente hispânico tiveram em Roma. Ainda deviam persistir as marcas desses tempos conturbados e ser recordadas algumas peripécias históricas, em especial dos conflitos internos em que a res publica se viu envolvida ao longo do meio século que o precedeu. A questão sertoriana em particular e as Guerras Civis entre César e Pompeio ainda estariam certamente bem vivas na memória dos seus coetâneos.

Se estivesse atento às novas obras que progressivamente iam transformando a paisagem urbana da capital do império, também não lhe teria escapado o facto de Marco Vipsânio Agripa providenciar o início da construção de um monumental pórtico, no qual se expunha publicamente um «mapa» do todo o orbe e onde se assinalariam as regiões e povos sob o domínio romano ${ }^{2}$. Nele figuraria a prouincia Lusitania que o genro de Augusto tão bem conhecia, ele

${ }^{1}$ Lens Tuero (1986).

${ }^{2}$ A própria existência deste mapa e a sua natureza têm sido objecto de ampla controvérsia, ainda não resolvida. No entanto, uma boa parte dos investigadores considera que as referências literárias, nomeadamente as diferentes alusões de Plínio-o-Velho, são claras a respeito da exibição pública no espaço do Pórtico Vipsânio de um «mapa» Nicolet (1988) 108-127; Salway (2001) 28-29; contra Brodersen (1995) 269-270. 
que viu o seu nome intimamente associado aos primeiros tempos da sua capital, Augusta Emerita, em especial à construção do seu teatro.

Aquele espaço público de Roma, conhecido justamente como Porticus Vipsania, conteria essa importante peça geográfica a que aludiria por diversas vezes Plínio-o-Velho (nat. 3, 16-17; 6, 139; 35, 25), manifestação do progresso dos conhecimentos, mas ao mesmo tempo um dos mais originais instrumentos da propaganda augustana. Ovídio teve certamente a oportunidade de constatar os avanços da sua construção num espaço situado junto ao Campo de Marte, graças à intervenção de Vipsânia Póla, sua irmã. O terreno tinha sido deixado em testamento por Marco Vipsânio, precocemente falecido no ano 12 antes da nossa era, e a obra viria a ser concluída por empenho do princeps.

Naturalmente, não the passariam despercebidos os novos desígnios que Augusto traçara para a Hispânia, em especial o projecto de promover a sua integral "pacificação», termo com que designou eufemisticamente as campanhas destinadas a submeter os irredutíveis Cântabros e Ástures, no extremo norte da Península.

2. No entanto, para o poeta Ovídio, afastadas já as suas pretensões a uma carreira política e com a sua vida pautada por outros interesses, os ecos dessa terra na orla do Oceano assumem aspectos muito distintos, mais ligados com a cultura letrada. Nos círculos literários de Roma, a imagem da Lusitânia assentava em peculiaridades que nada tinham que ver com os projectos augustanos ou as alterações políticas, administrativas e sociais que afectaram a nova província.

$\mathrm{Na}$ base do seu conhecimento concreto encontra-se, afinal, uma particularidade de natureza económica: as fabulosas riquezas do Tejo e as suas águas auríferas, promovidas no seu meio cultural a tópico bem conhecido e amplamente difundido, pelo menos desde que Catulo $(29,19)$ o transformou num paradigma poético ${ }^{3}$. Essa característica espantosa convertida em topos literário explica amplamente a razão pela qual Ovídio inclui na sua obra referências concretas à longínqua Lusitânia. A primeira ocorre nos seus Amores $(1,15,34)$, onde retoma o lugar-comum catuliano.

Mas o fabuloso rio entra igualmente no extenso elenco dos cursos de água atingidos pelo calor abrasador do carro do sol descontrolado, conduzido pelo inábil e imprudente Faetonte, episódio que ocupa uma parte das suas Metamorfoses $(2,241-259)$. Numa longa lista onde se alinham, entre outros, o Tánais, o Ismeno, o Erimanto, o Xanto, o Eufrates, o Ganges e o Histro e depois dele o Nilo, o Ebro, o Reno, o Ródano e o próprio Tibre, recebe uma referência especial o Tejo e o ouro que as suas águas arrastam. No caso do rio hispânico, a aproximação excessiva do carro do Sol desgovernado provoca, na visão poética de Ovídio, o maravilhoso fenómeno da fusão das pepitas transportadas nas suas águas («/.../ e o ouro que o Tejo arrasta no seu leito flui, derretido pelas chamas $\left./ . . . / »^{4}\right)$.

\footnotetext{
${ }^{3}$ Fernández Nieto (1970-71).

${ }^{4}$ Quodque suo Tagus amne vebit, fluit ignibus aurum (Ov., met. 2, 251).
} 
Ainda que se trate de uma alusão literária, enquadrada, como compete a uma obra deste tipo, num contexto de narrativas míticas, remete-se aqui para uma realidade confirmada historicamente, como o tem posto cada vez mais em evidência a investigação arqueológica mais recente. Tendo em conta a dimensão dos vestígios, pode considerar-se diminuta a informação da primeira metade do séc. XX, onde sobreleva uma alusão de Francisco Tavares Proença Júnior ${ }^{5}$ ao sítio de Lisga. Só nos finais da centúria, a pesquisa sistemática de Domergue sobre a mineração hispânica põe em evidência a amplitude da exploração, sublinhando a sua dispersão por quatro áreas: Mouriscas, Abrantes, foz do Zêzere e Milreu ${ }^{6}$. Esta última corresponde ao núcleo mais importante e desenvolve-se nas margens da Ribeira de Codes, hidrónimo a este título bem sugestivo, uma vez que deriva seguramente do lat. cos, cotis, «seixo» ${ }^{7}$. Este apelativo, que se repete numa atestação toponímica próxima, situada na sua margem direita, deriva da acumulação de seixos lavados, o mais evidente resultado da exploração mineira romana nessa região.

As observações de Domergue foram completadas pelas investigações de Sánchez-Palencia, que sublinhou a elevada capacidade produtiva desta região, em especial a das explorações das margens do Tejo, responsáveis por uma movimentação de aproximadamente $27000000 \mathrm{~m}^{3}$ de sedimentos ${ }^{8}$. O teor de ouro neles contido poderia variar de forma substancial, pelo que não é fácil fazer cálculos a respeito dos proventos que advinham desta exploração. A partir de um pressuposto de que nos primeiros $50 \mathrm{~cm}$ sobre a rocha se poderiam recolher $200 \mathrm{mg}$ e nos níveis superiores 2 a $80 \mathrm{mg}^{-9}$, imaginou-se uma produção média de $140 \mathrm{mg}$ de ouro por $\mathrm{m}^{3}$, pelo que a totalidade da exploração, só nesta área, poderia ter dado origem a mais de 3,5 toneladas de metal precioso ${ }^{10}$.

Os trabalhos de prospecção arqueológica levados a cabo posteriormente aumentaram de forma significativa as áreas em que se reconhece este tipo de actividade mineira. Carlos Batata foi o principal responsável pela identificação e divulgação dos mais recentes achados, dando conta de identificações que resultaram do empenhado trabalho de prospecção de várias pessoas. Numa publicação dedicada ao estudo da área correspondente às bacias do Baixo Zêzere e do Ocreza, bem como do território adjacente ao Tejo durante a Idade do Ferro e o período romano, o Autor dedicou uma atenção especial a este tema, dando conta da sua importância histórica e da enorme riqueza patrimonial

${ }^{5}$ Proença Júnior (1910) 9.

${ }^{6}$ Domergue (1987-88) 527-528.

7 Também se tem procurado ver no termo «conho» e no seu derivado «conheira» (nalguns casos «cunheira»), com o qual se designam estas acumulações de seixos, uma relação com este mesmo termo latino (BATATA (2006) 104). Esta interpretação carece, contudo, de uma explicação adequada no âmbito da fonética histórica.

${ }^{8}$ Sánchez Palencia (1989) 45-47.

${ }^{9}$ Sánchez Palencia (1989) 45-46.

${ }^{10}$ Batata (2006) 107. 
que representam estes vestígios ${ }^{11}$. Ao mesmo tempo pôs em evidência o desconhecimento que ainda marca o momento actual da investigação e a necessidade de desenvolver acções tendentes a minorar esta falha ${ }^{12}$.

$\mathrm{Na}$ margem esquerda os vestígios do Tejo parecem ser menos numerosos. No entanto, é amplamente conhecida uma outra área de exploração, bastante extensa, situada a jusante das Portas do Ródão, designada sintomaticamente como Conhal do Arneiro ${ }^{13}$.

Embora sejam estas as áreas em que mais indícios da actividade se identificaram, o âmbito da exploração aurífera na bacia do Médio e Baixo Tejo é consideravelmente mais extenso. Apresentaram-se recentemente, de forma circunstanciada, os resultados dos trabalhos de prospecção realizados numa área distinta, a de Penamacor-Meimoa ${ }^{14}$, na qual se tinham referenciado, há algumas décadas, os vestígios dessa mesma actividade extractiva ${ }^{15}$. As diferentes zonas de exploração poderiam ter correspondido, só neste caso, a cerca de 3500 $000 \mathrm{~m}^{3}$ de sedimentos movimentados. Para além disso, inventariam-se os sítios da bacia do rio Erges em que a pesquisa aurífera se desenvolveu, contribuindo para que progressivamente se possa ter uma ideia da real dimensão de uma actividade que tantos reflexos teve na literatura latina.

Para Ovídio, como para todos os poetas, o paradigma literário corresponde, todavia, ao do pesquisador que vai lavando pacientemente as areias que o rio arrasta, actividade paralela a esta, mas mais dificilmente de comprovar no plano arqueológico. A ela se tem atribuído, todavia, o topónimo «Oeiras», que, segundo a interpretação mais corrente, remontaria ao latim Aurarias $^{16}$, o que pressupunha a prática do garimpo nessa área da foz do Tejo pelo menos desde período romano. A riqueza proverbial resultaria, naturalmente, da progressiva erosão, ao longo de milénios, dos depósitos auríferos que se situavam no Tejo e nos seus afluentes, em especial aqueles a que já aludimos.

Totalmente distinta desta era a pesquisa sistemática e intensiva que a arqueologia atesta, resultado de um paradigma de exploração em grande escala dos recursos do território que caracteriza o período romano e se afirma com um dos traços mais marcantes da nova política augustana para as províncias. Esta encontra-se mais próxima da avidez e da auri sacra fames e corresponde a uma faceta distinta, menos apta a projectar-se como imagem poética.

$\mathrm{Na}$ generalidade, a exploração mineira constitui uma das actividades mais desenvolvidas na Hispânia, consequência da amplitude deste recurso que tornou a região famosa, pelo menos desde os seus primeiros colonizadores. Este autêntico Eldorado da antiguidade respondeu à sua verdadeira fama, especialmente a partir do início do principado, quando as intensivas explorações dos depósitos auríferos, em especial os da zona ásture, afluíram a Roma. Por isso

\footnotetext{
${ }^{11}$ Batata (2006) em especial 81-87, 104-107.

${ }^{12}$ Batata (2006) 82, 107.

${ }^{13}$ Calado, Calado (2002).

${ }^{14}$ Sánchez Palencia; Pérez García (2005).

15 Albertos; Bento (1977) 1200-1201; Domergue (1987-88) 512-513.

${ }^{16}$ Machado (1994) 1087.
} 
Plínio (nat.33,78), conhecendo bem esta realidade, não hesita em afirmar, cerca de um século mais tarde, que «nenhuma outra região da terra manteve ao longo de tanto tempo uma tão alta produtividade ${ }^{17}$. Naturalmente o enciclopedista, também ele leitor de Catulo e Ovídio, eleva o Tejo à condição de fenómeno digno de referência especial, colocando-o entre os mais famosos rios auríferos, a par dos notáveis e distantes Pactolo e Ganges (Plin., nat. 33,66), símbolos romanos dessa riqueza mítica, sintomaticamente projectada para territórios mais distantes.

3. Mas o interesse romano pelas províncias hispânicas e pela Lusitânia em particular ultrapassa amplamente a abundância metalífera. $\mathrm{O}$ completo programa de Augusto para a reorganização das províncias, progressivamente concretizado ao longo da existência do poeta que se homenageia, assume múltiplas vertentes, produz um impacte social e político de muito maior dimensão. No âmbito das iniciativas imperiais, tão inovadoras quanto de amplo alcance, a exploração dos recursos mineiros, transversal a toda a presença romana, tem essencialmente um impacte económico, especialmente em Roma. Mas o alcance das transformações devidas à sua política não encontra paralelo ao longo da história do domínio romano nesta circunscrição.

A vertente mais visível é, naturalmente, a própria criação da província, em resultado da separação da Hispânia Ulterior em duas entidades com características bem marcadas: a Lusitânia, que ganhara finalmente a condição de provincia pacata, depois de mais de um século de instabilidade; e a Bética, numa fase mais avançada, onde o desenvolvimento urbano tinha atingido dimensões excepcionais para o Ocidente.

Augusto interpretou uma política decididamente reformadora que César tinha prenunciado. Uma das facetas dessa continuidade de acção diz respeito à promoção jurídica das cidades, aspecto com substancial impacte nas comunidades locais mais desenvolvidas. Se César tinha empreendido uma iniciativa clara de alargamento dos benefícios da cidadania romana a um conjunto já significativo de lugares hispânicos ${ }^{18}$, o seu filho adoptivo confere-lhe uma outra dimensão. No caso concreto do que vem a ser a província da Lusitânia, a acção de Octaviano/Augusto confere estatutos privilegiados pelo menos a Pax Iulia $^{19}$, Felicitas Iulia Olisipo e Augusta Emerita, para além do direito latino às localidades de Myrtilis, Salacia e Ebora.

A reorganização provincial implica, no entanto, a criação de um total de 45 entidades autónomas - as ciuitates, cujo nome é possível determinar na sua quase totalidade. Uma grande parte situa-se na área entre Tejo e Douro, uma

${ }^{17}$ Guerra (1995) 133-134.

${ }^{18}$ Considera-se habitualmente que devem ao ditador o seu estatuto colonial Norba Caesarina, Scallabis (Praesidium Iulium) e Mettelinum, embora nem todas estas atribuições reúnam o consenso.

${ }^{19}$ Esta posição é sustentada por Vittinghoff (1952) 109, n. 4, Galsterer-KröLl (1975) 122 e n. 11 e FARIa (1986); (1989); (1997); (2001) 352-353. Para um elenco dos autores que atribuem a César esta promoção v. FARIA (2001) 353. 
região onde as transformações culturais se encontravam num estádio menos avançado que no resto da província. Estas realidades correspondiam, pois, a comunidades livres (na expressão latina, suas leges habent, «regem-se pelas suas próprias leis»), mas geralmente stipendiariae, isto é, sujeitas a tributo.

Sem qualquer tradição de uma estrutura similar, esta área da Hispânia assistiu a um processo de constituição destas realidades para as quais se estabeleceu, de forma muito concreta, um território e uma sede administrativa, a que se atribuiu nome oficial. Uma das facetas bem conhecidas deste esforço organizativo consistiu na delimitação das fronteiras dessas novas entidades, com a implantação de monumentos que na terminologia latina se designavam, sugestivamente, como terminus augustales. Estes vestígios epigráficos, pelas suas características e pelo seu texto, muito para além de uma função prática de delimitação, destinam-se igualmente a afirmar a autoridade do imperador, transformando-se em demonstrações do domínio de Roma.

Estas novas realidades aparecem habitualmente designadas na epigrafia como ciuitates, precisamente porque a sua essência reside, acima de tudo, no facto de serem comunidades de cidadãos, dotadas de autonomia, embora se organizem de acordo com algumas linhas gerais comuns. Os seus magistrados e as assembleias obedecem, como o patenteia a documentação epigráfica, a um modelo muito próximo, de acordo com o estatuto jurídico de cada uma.

Progressivamente, o centro dessas entidades assume um aspecto urbano, mais ou menos monumental, apresenta estruturas que obedecem a um paradigma arquitectónico que, em última análise, é fornecido pela própria cidade de Roma. Neste modelo urbanístico entram necessariamente algumas componentes essenciais que paulatinamente se vão constituindo, sem que haja necessariamente uma sincronia entre as diferentes comunidades. Em primeiro lugar impõe-se, pela sua importância como centro cívico, o forum, núcleo e símbolo da própria vida pública, com as características e os elementos adequados a cada caso. $\mathrm{Na}$ sua diversidade, este edifício obedece, todavia, a um conjunto de parâmetros bem conhecidos, reflexo dos modelos instituídos na cultura romana e executados de acordo com um rigoroso plano arquitectónico, resguardado de qualquer improvisação. Nele se integra, por norma, o templo, estrutura que encerra a duplicidade da vida cívica, na qual confluem interesses de ordem social ou «política» e de natureza religiosa. Dois campos que nas estruturas mentais romanas deste período andam intimamente ligadas.

Naturalmente, os elementos que integram estas comunidades são socialmente muito diferenciados. Na esfera dos homens livres, ressalta a dicotomia peregrinus/ciuis romanus, que opõe o membro destas realidades hispânicas ao que acedeu já aos privilégios da cidadania romana. A possibilidade de os primeiros acederem à outra condição, com mais privilégios, torna-se cada vez mais viável, à medida que se vão estendendo as promoções jurídicas das próprias cidades. A concessão de estatutos privilegiados e essas comunidades afirma-se precisamente como um dos meios mais frequentes de promover as elites locais, abrindo precisamente o caminho a esta mudança de condição. 
Deste modo, a decisão de Augusto de promover juridicamente os principais centros da Lusitânia revela-se uma medida com enorme impacte na integração das populações locais, em especial dos seus elementos preponderantes. Estas elites, que progressivamente se dispõem à participação cívica, são também as responsáveis pelas sucessivas manifestações públicas de conformidade com a cultura romana. Nesta fase e devido à política augustana de alargamento da ciuitas, amplia-se o processo de promoção de hispânicos que, sem perderem essa sua condição, ganham um novo estatuto jurídico.

Estas transformações acompanham a crescente prosperidade e bem-estar das comunidades, e essa situação associa-se, na mente de muitos, às alterações que a ordem romana trouxe consigo. Por essa razão os sentimentos de revolta contra Roma não são entendidos por muitas das populações lusitanas que, nesta fase, já não alimentam qualquer vontade de ruptura com o modelo social e político que se vai impondo.

4. O processo de integração das populações hispânicas no âmbito das comunidades romanas encontra-se igualmente documentado, para a fase augustana, em alguns textos epigráficos. Um dos mais sugestivos exemplos é proporcionado por um monumento originário de Alcácer do $\mathrm{Sal}^{20}$, um grande bloco de granito que chama a atenção desde logo por este facto, uma vez que se insere num âmbito em que o suporte das inscrições irá ser, por via da regra, o mármore. O indivíduo revela uma antroponímia muito característica,constituída por um nome único seguido do patronímico, obedecendo ao modelo habitual no ocidente da Hispânia. O apelativo Boutius não deixa lugar a dúvidas sobre a sua pertença à tradição onomástica dessa mesma região, constituindo, para além disso, um dos nomes pessoais mais amplamente atestados no território da Lusitânia, onde ele é particularmente abundante, registando ainda uma presença, mas mais escassa, nos âmbitos ásture e celtibérico ${ }^{21}$. A sua ocorrência na epigrafia romana da antiga Salacia constitui uma excepção, uma vez que se trata precisamente do único caso seguro desta localidade que representa uma tradição pré-romana de origem indo-europeia ${ }^{22}$.

Ao contrário, o termo Vicanus pertence ao âmbito latino, fazendo parte do amplo conjunto onomástico que as populações lusitanas adoptam. Este é apenas um dos muitos exemplos que ilustram uma tendência para a progressiva

${ }^{20}$ Trata-se de CIL II, $5182=$ IRCP184 Imp(eratori) Caesari divi f(ilio) Augusto / pontifici maxumo co(n)s(uli) XII / trib(unicia) potestate XVIIII / Vicanus Boutif(ilius) / sacrum - «Vicano, filho de Bôucio, consagrou ao imperador César Augusto, filho do Divino, pontífice máximo, cônsul pela décima segunda vez, com o décimo nono poder tribunício».

${ }^{21}$ VAllejo (2005) 216-222.

${ }^{22}$ É significativo, para compreender a diversidade cultural deste importante pólo comercial, que o outro vestígio onomástico não pertencente às línguas clássicas corresponda ao nome Bocchus, nome de origem norte-africana (Albertos (1966) 56) ou mesmo púnico (Mantas (1996) 350) que ostentam algumas personagens ilustres de Salacia nesta fase precoce do império. Um deles seria o célebre autor de uma obra sobre a Lusitânia, citado por Plínio-o-Velho na sua obra enciclopédica (Etienne (1958) 122-124; Guerra (1995) esp. 138-139; Guerra (2002) 182; Fernandes (2002); Gonzalez Herrero (2002) esp. 52-53). 
vulgarização de antropónimos de origem itálica, reflectindo as transformações culturais que marcaram já a geração anterior, a dos seus pais. Deste modo, o fenómeno de alteração cultural pode remeter-se, no caso vertente, para um momento que deveria corresponder ao início do principado, fase em que o processo de romanização ganha uma nova dinâmica, em especial em cidades que receberam alguns privilégios, como é o caso de Salacia.

Apesar da sua proveniência exógena, o termo Vicanus regista-se, na Lusitânia, apenas entre as populações locais, uma vez que as três ocorrências ${ }^{23}$ até ao momento atestadas respeitam todas elas a peregrini. Tendo em consideração exemplos dos quais subsiste uma documentação mais abundante, pode afirmarse que este se poderia integrar no conjunto dos elementos antroponímicos latinos que se implantaram neste meio provincial do Ocidente. Note-se que certos nomes romanos adquiriram na Lusitânia uma particular difusão, nunca atingida em nenhum outra parte do império, nem mesmo na própria $V r b s^{24}$. Por esta razão, um nome como Vicanus ilustra de forma adequada a simbiose que se opera no domínio onomástico e, de uma forma mais ampla, em todo o âmbito cultural.

Juridicamente, a nossa personagem, Vicanus Bouti f(ilius), integra-se na categoria dos peregrini, uma vez que se trata de um indivíduo de nascimento livre, mas que ainda não acedeu ao privilégio da ciuitas romana, embora detenha a cidadania local ${ }^{25}$ ). Desconhecemos, todavia, por que motivos e em que qualidade promove uma homenagem pública a Augusto, no período em que o imperador exerceu o décimo nono poder tribunício (entre 1 de Julho de 5 a. C. e 30 de Junho do ano seguinte).

Não restam dúvidas sobre a natureza desta dedicatória, definida na própria epígrafe como um objecto sagrado (sacrum), mas não se indica qualquer cargo público que esperaríamos ver citado num monumento em que se promove aparentemente um acto oficial. Faz parte, naturalmente, do conjunto de vestígios que atestam o culto imperial, uma das formas pelas quais as populações do mundo provincial exprimem a sua adesão aos modelos políticos, religiosos e culturais romanos.

A vida urbana e a actividade cívica desenvolvem-se progressivamente nestas comunidades gerando-se no seu âmbito estes vestígios materiais que exprimem

${ }^{23}$ As restantes são provenientes da ciuitas Igaeditanorum e de Herguijuela, Cáceres, respectivamente: Almeida (1954) 233, n. 147 = ILER 4053, 6257-Virio Tangini et / Sunuae Vigani Flac/cus et Longinus parenti/bus suis faciendum curarunt / s(it) v(obis) t(erra) l(euis); e Gimeno; Stylow (1993) 161, n. 57 = AE 1993, $973=$ HEp-05,211 - Vicanus $/$ Talaba/rif(ilius) an(norum) $L X / h$ (ic) s(itus) s(it) t(ibi) t(erra) / [l(evis)] fili(i) f(aciendum) c(uraverunt).

${ }^{24}$ É o caso, por exemplo de Avitus / Avita, que se regista 152 vezes na Lusitânia (Atlas, 410) ou o de Amoenus / Amoena que surge 73 vezes (Atlas, 85-87, 410), um número bastante superior ao que ocorre em Roma. Este último corresponderia ao que se designa como um Deckname, isto é, um elemento que corresponderia à tradução latina de um local (Atlas, 410).

${ }^{25}$ Etienne (1958) 391 considera Vicanus «un romain de fraîche date», expressão que não implica certamente a obtenção da cidadania. Tendo em consideração a sua estrutura onomástica e a ausência de qualquer outro elemento que sustente essa possibilidade, deve tomar-se como um peregrinus: v. Le Roux (1996) 246. 
de forma clara a integração nelas dos elementos locais de maior preponderância. As transformações não se traduzem apenas numa maior pacificação do território, numa vantagem para os Romanos que decidiram trocar o solo itálico pelas longínquas terras do ocidente. Provoca igualmente a promoção das elites locais que exploram as novas oportunidades que o vasto império romano agora oferece. E, naturalmente, quando se fala das potencialidades do comércio, não pode esquecer-se que a antiga Salacia reúne condições excepcionais, como o atestam os vestígios materiais de amplos contactos com o mundo mediterrâneo mesmo em fase anterior à romanização $0^{26}$.

Nestas cidades desenvolvidas e abertas às novas ideias, as tradições exógenas implantam-se como alguma facilidade. Uma das marcas dos novos tempos reflecte-se na difusão dos hábitos epigráficos, em que o monumento promovido por Boutius se insere. O período correspondente ao principado de Augusto e, portanto, o da vida do poeta que recordamos, marca, também neste domínio, o surgimento de uma nova era. Não é apenas na Hispânia que se assiste nesta fase a uma explosão das manifestações epigráficas, fenómeno que atingem diversas esferas, seja do âmbito público ou privado. Escrever em língua latina e usando o alfabeto que o conquistador desenvolveu representa uma das faces da adesão cultural das comunidades locais ${ }^{27}$.

5. Um outro notável documento epigráfico coetâneo do anterior e também do Sulmonense registou-se em Idanha-a-Velha, a antiga ciuitas Igaeditanorum. Referir-se-ia, segundo a interpretação mais aceitável, a um relógio que viria a ser colocado em lugar público ${ }^{28}$ - o texto reporta-se a um orarium, termo que os diferentes autores têm considerado a alteração de uma grafia horarium ${ }^{29}$. A inscrição (HEp 2, 770 = AE 1961, 349 = AE 1967, 144 = AE 1992, 951) deve interpretar-se da seguinte forma:

Q(uintus) Tallius Sex(ti) f(ilius) Papi(ria) Augu(stanus) / (b)orarium donavit / Igaiditanis l(oco) a(dsignato) f(ecit) per mag(istratum) / Toutoni(i) Arci(i) f(ilii) Malgeini Manli(i) f(ilii) / Celti(i) Arantoni(i) f(ilii) / Ammini Ati(i) f(ilii) / L(ucio) Domitio Aenobarbo / P(ublio) Cornelio Scipione co(n) [s(ulibus)] $]^{30}$

${ }^{26}$ Arruda (2000) 5-7 a 5-59; 5-86 a 5-88.

${ }^{27}$ EncARnação (1995) 257.

${ }^{28}$ Para o estudo deste monumento e do seu alcance histórico continua a ser fundamental Mantas (1988).

${ }^{29} \mathrm{Na}$ realidade, não seria fácil explicar a razão deste acto público se se admitisse que o objecto em causa seria uma pequena peça de tecido, ou um sudarium, o sinónimo que os dicionários e enciclopédias registam para este termo latino orarium (v., por exemplo, Daremberg; SAglio, IV (1877-1919) 223-225).

30 A interpretação desta extraordinária epígrafe tem suscitado opiniões divergentes, especialmente em quatro aspectos distintos: 1. o nomen da pessoa que ofereceu o relógio corresponde certamente Tallius, de acordo com autópsia e a lição seguida por alguns autores - Palomar (1956) 100; Sá (2007) 61, n. 54 -, preterindo a lição Iallius cfr. VAllejo, (2005) 491 e que algumas fotos põem em evidência; o gentilício é raro na Hispânia, mas atestado igualmente em Villanueva de la Serena (Badajoz), onde se regista um Ta(l)lius Q.f. Pap. (HEp 4,186 ), soldado da legião $X$, também ele emeritense; 2 . A investigação tem vindo a consolidar 
Quinto Tálio, filho de Sexto, da tribo Papíria, natural de Augusta (Emerita), ofereceu o relógio aos Igeditanos; no lugar concedido o fez por intermédio da magistratura de Toutónio, filho de Árcio, Malgeino, filho de Mânlio, Célcio, filho de Arantónio, Amino, filho de Ácio, sendo cônsules Lúcio Domício Aenobarbo e Públio Cornélio Cipião.

O monumento, datado pelas referências aos magistrados epónimos de Roma do ano 16 a. C., constitui também ele a primeira manifestação epigráfica documentada na ciuitas Igaeditanorum e uma das mais antigas inscrições latinas da Lusitânia. Representa, por todas estas razões, um dos mais sugestivos elementos das transformações culturais que se registam na Lusitânia nos alvores do principado ${ }^{31}$. Um cidadão de Augusta Emerita, mas igualmente ciuis romanus, demonstra publicamente o seu empenho em contribuir para uma renovação urbana neste núcleo, escolhido para sede de uma comunidade cívica recentemente criada. Como já se sublinhou anteriormente ${ }^{32}$, este documento epigráfico marcaria o progressivo funcionamento das instituições políticas locais. Entre elas se encontra a magistratura local, formada por um colégio de quatro indivíduos, que nestas circunstâncias se associa igualmente a dedicatória particular, mas com interesse público, proporcionando o local para monumento ${ }^{33}$.

A personagem em causa, pela sua onomástica e tendo em consideração a cronologia do monumento, não se integra na componente demográfica de origem hispânica, mas integra as populações exógenas que se fixam nesta região ao longo da fase inicial do processo de romanização. À mesma gens deverá, de resto, pertencer um soldado da legio $X$ uma vez que também ele é portador deste gentilício raro, de origem latina escassamente representado no mundo romano ${ }^{34}$. As atestações conhecidas apresentam grande dispersão, encontrando-se na Gália Narbonense (CIL XII, 511, de Aix-en-Provence), na Gallia Belgica (XIII, 3416, de Reims), na Germânia (AE 1979, 433, de

a ideia de que à tribo se seguiria a indicação de origo, pelo que as propostas de Augu(rinus) ou Augu(stinus) foram justamente preteridas em favor de Augu(sta) ou Augu(sta Emerita) (Mantas (1988) 421-422; SÁ (2007) 61, n. 54); no entanto, tendo em conta a cronologia da epígrafe e como reconhecem Edmondson, Hidalgo (2007) 496-498 em situações similares, parece preferível desenvolver como Augu(ustanus); 3. A abreviatura L. A. F. foi já interpretada como l(ibens a (nimo) f(ecit), como l(ocus) a (d signatus) f(uit) e ainda como l(oco) a(ccepto) f(ecit); 4. Por fim, não se apresentou, que eu saiba, uma solução que permita resolver a incongruência flexional que resultaria da interpretação como per mag(istros) da sequência imediata; penso que uma opção por per mag(isterium) ou mag(istratum) poderia contornar esta dificuldade.

31 A cronologia do monumento e a sua manifesta importância no contexto regional levaram Etienne (1989) 261-262 a considerar provável o seu vínculo com a criação da província da Lusitânia.

${ }^{32}$ Mantas (1988) 422.

${ }^{33}$ Infelizmente ainda não é possível garantir com segurança qual o nome que assumia essa magistratura tipicamente local, uma vez que a interpretação da abreviatura MAG. que a epigrafia sistematicamente atesta, continua a oscilar entre mag(istri) e (mag(istrati).

${ }^{34}$ Schultze (1904) 94, 425; Solin; Salomies (1994) 180; contra Palomar ( 1954) 100. 
Mainz), em Roma (CIL VI, 10130 e talvez 22155, esta sob a forma Thallius) e em Corinto (CIL III, 13692), para além de um registo de proveniência desconhecida (AE 1985, 994) e um outro colhido numa referência literária (Tac. ann. 14,50).

Ainda que não seja possível identificar a origem concreta da gens a que pertence o benemérito da ciuitas Igaeditanorum, esta figura representa bem os estratos sociais com fortes ligações à cultura romana que em determinado momento se instalam em importantes centros políticos e administrativos. Augusta Emerita, com o seu estatuto colonial e na sua qualidade de capital da província, converte-se, naturalmente, no pólo de atracção dos elementos de origem itálica e, ao mesmo tempo, no paradigma do desenvolvimento urbano, nas suas diversas vertentes. A cidade e os seus habitantes, nos quais se integram desde fase precoce veteranos que tinham participado nas Guerras contra Cântabros e Ástures, assumem-se como modelo para as elites locais.

Não surpreende, por isso, estas populações com vivência urbana manifestem algum empenho em contribuir para a promoção de outros núcleos, com os quais naturalmente se começam a estabelecer, nesta fase, importantes ligações. Quinto Tálio distingue-se, neste processo, como um dos exemplos mais precoces deste encaminhamento progressivo das transformações culturais dos centros principais para os aglomerados periféricos, de forma a que estes, por sua vez, se constituam como os elementos dinâmicos do processo de alteração das mentalidades.

6. Uma outra faceta desta acção de elementos exógenos manifesta-se num tipo de vestígios epigráficos conhecido como as tesserae hospitales. Tipicamente, correspondem a documentos inscritos em tabellae de bronze nos quais se estabelece formalmente o hospitium, um tipo de vínculo bem conhecido em todo o mundo mediterrâneo, com alguma tradição em território hispânico, em especial na área celtibérica ${ }^{35}$.

No território da Lusitânia identificaram-se, há algumas décadas, dois destes bronzes inscritos, ambos provenientes da mesmo sítio e nos quais os outorgantes hispânicos se identificam como Turduli Veteres. Estes importantes achados provêm de Pedroso, Vila Nova de Gaia, em concreto do Castro do Montemurado, tendo sido competentemente estudados na década de $80^{36}$. Os textos correspondem genericamente a um modelo bem conhecido neste tipo de manifestações. O primeiro deles, datável através da referência aos cônsules do ano 7 da nossa era, isto é, do último ano que Ovídio passou em Roma antes do seu exílio, diz o seguinte:

Q(uinto) Caecilio Metello A(ulo) Licinio co(n)s(ulibus) / D(ecimus) Iulius D(ecimi) f(ilius) Gal(eria) Cilo hospitium fecit / sibi liberis posterisque suis cum Nigro / et Rufo et Prisco Turdulis Veteribus / liberis posterisque eorum;

${ }^{35}$ Repertórios e sínteses das principais questões relativas às tésseras celtibéricas podem encontrar-se em UNTERMANn (1997) 375-378; 538-722, e JoRdÁn (2004) 237-293.

${ }^{36}$ Silva (1983); (1984). 
Sendo cônsules Quinto Cecílio Metelo e Aulo Licínio, Décimo Júlio Cilão, filho de Décimo, da tribo Galéria, fez um pacto de hospitalidade, para si, seus filhos e descendentes com Nigro, Rufo e Prisco, Turduli Veteres, com seus filhos e descendentes.

O outro, dois anos mais tardio e, portanto, coetâneo do início do desterro do poeta na longínqua Tomos, apresenta um texto similar:

Q(uinto) Sulpicio Camerino C(aio) Poppaeo / Sabino co(n)s(ulibus) / D(ecimus) Iulius M(arci) f(ilius) Gal(eria) Cilo hospitium fecit / cum Lugario Septanii f(ilio) ex Turduleis /Veteribus eumque et leiberos(!) posteros/que eius in fidem clientelamque / suam recepit leiberorum(!) posterorum/que suorum egit / Lugarius Septanii;

Sendo cônsules Quinto Sulpício Camerino e Gaio Popeu Sabino, Décimo Júlio Cilão, filho de Marco, da tribo Galéria, fez um pacto de hospitalidade com Lugário, filho de Septânio, dos Turduli Veteres, e recebeu-o a ele, aos seus filhos e descendentes na fides e clientela dele, dos seus filhos e descendentes. Lugário, filho de Septânio, o fez.

Encontramo-nos, pois, perante documentos bastante precoces no contexto da epigrafia hispânica, nos quais ainda se manifesta uma particularidade que ainda revela bem um carácter «arcaico», manifesto nas grafias leiberis, leiberorum e Turduleis.

Estas manifestações epigráficas ilustram de forma exemplar uma das facetas que assumiu a integração das populações hispânicas na nova realidade social e política. Neste caso patenteia-se a criação de vínculos jurídicos com um cidadão romano privado, como impõem as normas legais. Os termos em que se estabelece o contrato não são, textualmente, o mesmo. No primeiro caso fala-se apenas de hospitium, o que poderia ser interpretado como uma relação entre partes que detêm igual peso. No entanto, na outra epígrafe torna-se claro que uma personalidade relevante da administração romana oferece a sua protecção a autóctones, integrando-os na sua clientela ao mesmo tempo que aceitam pautar as suas relações pelo valor da fides, circunstância inerente a estas situações.

A obrigação apenas vincula, de acordo com o formulário habitual, os contratantes, os seus filhos e descendentes. De qualquer modo, ainda que este actue nessa condição, tal como acontece com o conhecido caso de tabula patronatus da Juromenha (AE 1967,125), em que uma das partes é constituída precisamente pelo legado de Augusto na província, também aqui este contrato assume sem dúvida um significado mais amplo do que o simples acordo entre pessoas.

Não será difícil imaginar que tanto os três elementos indígenas referidos no primeiro texto como o segundo outorgante do outro fazem parte da elite local. Embora actuem em seu nome pessoal ou da sua família, há evidentemente alguma repercussão destes acordos nos interesses da comunidade que 
representam. Não será um mero acaso que em ambas circunstâncias se indique explicitamente a sua integração nos Turduli Veteres, já então organizados em comunidade cívica. Também não pode ser irrelevante o facto de os dois bronzes se encontrarem juntos numa mesma habitação, ainda que o nome dos intervenientes locais seja distinto.

Todavia, do ponto de vista formal, este documento jurídico não se estabelece com uma entidade colectiva, tal como acontece, por exemplo, na tabula Lougeiorum (Dopico, 1988, 11) na qual se ligam pelo hospitium Gaio Asínio Galo e a ciuitas que deu o nome ao documento, representada por dois legati; ou na tessera de Castromao, que consagra um pacto de hospitalidade entre Gaio António Áquilo, prefeito da I coorte de Celtiberos, e a ciuitas do Coelerni (AE 1972, 282 = AE 1973, 295). Mesmo nestas circunstâncias, não se altera a carácter privado dos vínculos jurídicos estabelecidos e com alguma frequência associados às transformações ditadas pelo processo de urbanismo e de transformação política das realidades locais ${ }^{37}$.

No caso dos Turduli , a subscrição do acordo em fase relativamente precoce e a sua renovação pouco depois com um novo contratante hispânico revelam bem a dimensão das transformações sociais e culturais neste território da Lusitânia «profunda». Afastados ainda da ciuitas romana, estes indivíduos adquirem, por esta via, um protecção jurídica que lhes advém de uma forma de patronato associada às relações de hospitalidade, circunstância especialmente clara no segundo documento. Os pactos consagram, em primeiro lugar, a integração das elites numa esfera marcadamente romana, contribuindo desta forma para uma progressiva inclusão de toda a população num ambiente mais caracteristicamente urbano, onde se vai impondo cada vez mais a participação na vida cívica.

7. As quatro décadas que compreendem o principado de Augusto, período no qual Ovídio vive em Roma e, por fim, no exílio, encontram-se repletas de indícios de uma profunda transformação da Lusitânia. Não se trata, naturalmente, de um processo brusco, mas o panorama social e político da província apresenta exemplos que ilustram alterações muito significativas.

Essas transformações envolvem ritmos muito diferentes, algumas delas rápidas e, por isso, nem sempre acompanhadas por todos. $\mathrm{Na}$ organização do território e no desenvolvimento urbano registam-se amplas novidades e percebe-se com clareza o forte impacte da mudança. Ao contrário, nos ambientes rurais persistirão ainda durante muito tempo velhas tradições locais. $\mathrm{Na}$ perduração da língua, dos cultos e da onomástica pessoal se representa uma tendência conservadora destes espaços, atestada em particular num número muito amplo de monumentos epigráficos.

Mas estes mesmos vestígios constituem, ao mesmo tempo, a mais eloquente demonstração de que esses ambientes mais conservadores acompanham o processo e não ficam indiferentes à nova vaga cultural de quem preside à

\footnotetext{
${ }^{37}$ Le Roux (1995) 90-91.
} 
reorganização do território. Naturalmente, a diversidade do mundo hispânico no plano geográfico, étnico, linguístico, cultural, económico e social implica igualmente que sejam muito diferenciadas as formas e os resultados que esse percurso assume.

Ilustraram-se algumas situações exemplares, quase sempre concludentes indícios da mudança marcada pela cultura de matriz itálica. De qualquer modo, os exemplos referidos traçam apenas um perfil bastante incompleto dessa nova época e das suas inúmeras novidades. Ainda que se exponha aqui uma visão muito parcelar, creio, todavia, ilustrar-se bem a dimensão e alcance das transformações que afectaram a ainda recente província. No quadro necessariamente fragmentário que a historiografia vai tentando reconstruir, estes tópicos representam algumas das facetas mais significativas desse paulatino processo de mudança. Acentua-se, em particular, o impacte perceptível nos espaços urbanos, aqueles em que os seus efeitos adquirem maior visibilidade e mais ampla dimensão. $\mathrm{Na}$ realidade, se existe alguma grande novidade que a romanização traz à maioria das regiões em análise, é sem dúvida o processo de urbanização, com todas as implicações no plano económico, social, político e cultural.

Por isso, uma das palavras-chave neste contexto é mesmo o termo ciuitas, na sua polissemia: a comunidade cívica autónoma a que se pertence e na qual se exercem as responsabilidades que incumbem a cada um; o território e o seu centro urbano, no qual se elevam as estruturas monumentais, espaço em que se exercem os deveres da cidadania. Os Lusitanos integraram portanto uma palavra nova no seu vocabulário, aquela que para o Ovídio exilado perdera já todo seu sentido, a mesma que se recorda a cada um de nós a cada momento: a que nos remete para a nossa inalienável condição de cidadãos, de ciues, agora de uma cidadania universal. 